\title{
Analysis on Production Efficiency of Forest Land in the Main State - owned Forest Regions of China
}

\author{
Guo Zhiqin ${ }^{1, *}$, Xiong Feng \\ School of Business Administration, Hohai University, Changzhou Jiangsu, China
}

Email: 20111843@hhu.edu.cn

\begin{abstract}
Development of forestry is an important task of building ecological civilization. Operation of state-owned forest regions has changed from economic goal to ecological goal which aims to turn green hills and clear waters into mountains of gold and silver. This paper constructs an indicator of production efficiency of state-owned forest land by using DEA method, and calculates annual production efficiency of state-owned forest regions with the data of yearbook of forestry economy in 2011-2015. The results show that forest production efficiency of Jilin Province and Inner Mongolia Autonomous Region is the highest while Yunnan, Xinjiang, Gansu, Sichuan and Shaanxi provinces have low state-owned forest production efficiency, with room for improvement.
\end{abstract}

Key words: state - owned forest, production efficiency, DEA

\section{Introduction}

Nationwide implementation of natural forest protection projects, ecological construction projects marks the historic transition of Chinese forestry as it formally enters ecological construction orientation from timber production orientation. Nature and functions of state-owned forest also undergo significant changes from the previous lumbering \& timber production to afforestation \& protection, with its output experiencing great changes. With the input and main output of state-owned forest farms as indicators, this paper analyzes the current production efficiency of state-owned forests by using DEA data envelopment method, and tries to compare production efficiency of state-owned forest areas in different provinces, to provide reference for development of state-owned forests.

\section{Research methods and model selection}

DEA method was first proposed by Farrell [2] and later developed into CCR model by Chames, Cooper and Rodes [9]. In 1957, Farrell, in his analysis of British agricultural productivity, proposed a method to measure production efficiency. He used "uninformed production function" instead of common "default function" to estimate efficiency value, and solved efficiency trimline with mathematical planning, which can be seen as DEA prototype [2]. In 1978, American operation researchers A.Charnes and W.W.Cooper, based on Farrell (1957) model, formally proposed a multi-input multi-output analysis based on relative efficiency - data envelopment analysis (DEA). The core idea is to find the optimal solution with mathematical planning to evaluate multiple input and output "units" or "sectors"(called decision-making unit, referred to as "DMU, Decision Making U-nits "): that is, with multiple DMU as evaluation groups, through the analysis of input or output ratio, take weight of each input or output indicator of DMU as variable for evaluation operation, to determine effective production frontier, and according to distance between DMU and effective production frontier, determine whether DEA is valid with regard to DMU, use projection method to indicate reasons for non-DEA effective or weak DEA effective DMU and propose direction and extent for improvement [3 ].

The fundamental characteristic of DEA method is that it measures relative efficiency of input and 
output of each DMU by using the effective frontier of production possibility set of the input and output data of decision unit. Therefore, this method does not involve parameter estimation and weight determination problem. In this paper, efficiency of forestry production in different provinces of China's major state-owned forest regions is evaluated on the basis of DEA's CCR model.

\section{Choice of indicators and data sources}

Use of DEA model in evaluation of production efficiency of state-owned forests in China needs determination of input indicators and output indicators. Indicator system is the basis for determining whether the evaluation results are scientific. To construct a scientific evaluation indicator system of production efficiency of state-owned forest land, we must first ensure that the indicator items can reflect inputs and outputs of state-owned forest production in all fields and meet the systematic requirements. Secondly, we should ensure that input / output are uniform in specification. Furthermore, we should consider availability and accuracy of indicator data. Taking into account the above factors, the input indicators are determined as the number of employees at the end of the year and fixed investment, timber production, output of 11 kinds of non-timber major forest products and number of forest tourists. The above data of the indicators come from 2011 - 2015 "China Forestry Statistical Yearbook".

\section{Empirical process}

According to the research design of this paper, the output orientation model of CCR is selected, and 2011-2015 input and output factors-related data of forestry production in seven provinces in China's major state-owned forest regions are input respectively. The operation results are as follows:

Table 1: DEA calculation result table

\begin{tabular}{|c|c|c|c|c|c|c|c|c|}
\hline \multicolumn{3}{|c|}{2011} & \multicolumn{3}{|c|}{2012} & \multicolumn{3}{|c|}{2013} \\
\hline DMU & Ranking & Score & DMU & Ranking & Score & DMU & Ranking & Score \\
\hline $\begin{array}{c}\text { Inner } \\
\text { Mongolia }\end{array}$ & 1 & 1.000 & $\begin{array}{c}\text { Inner } \\
\text { Mongolia }\end{array}$ & 1 & 1.000 & $\begin{array}{c}\text { Inner } \\
\text { Mongolia }\end{array}$ & 1 & 1.000 \\
\hline Jilin & 1 & 1.000 & Jilin & 1 & 1.000 & Jilin & 1 & 1.000 \\
\hline Xinjiang & 1 & 1.000 & Xinjiang & 1 & 1.000 & Shaanxi & 1 & 1.000 \\
\hline Gansu & 1 & 1.000 & Gansu & 1 & 1.000 & Gansu & 4 & 0.579 \\
\hline Yunnan & 1 & 1.000 & Shaanxi & 5 & 0.730 & Sichuan & 5 & 0.508 \\
\hline Sichuan & 6 & 0.442 & Yunnan & 6 & 0.431 & Xinjiang & 6 & 0.468 \\
\hline Shaanxi & 7 & 0.403 & Sichuan & 7 & 0.320 & Yunnan & 7 & 0.327 \\
\hline & 2014 & & & 2015 & & & $2011-201$ & \\
\hline DMU & Ranking & Score & DMU & Ranking & Score & DMU & Ranking & Score \\
\hline $\begin{array}{c}\text { Inner } \\
\text { Mongolia }\end{array}$ & 1 & 1.000 & $\begin{array}{c}\text { Inner } \\
\text { Mongolia }\end{array}$ & 1 & 1.000 & $\begin{array}{c}\text { Inner } \\
\text { Mongolia }\end{array}$ & 1 & 1.000 \\
\hline Jilin & 1 & 1.000 & Jilin & 1 & 1.000 & Jilin & 1 & 1.000 \\
\hline Xinjiang & 1 & 1.000 & Xinjiang & 1 & 1.000 & Xinjiang & 1 & 1.000 \\
\hline Sichuan & 1 & 1.000 & Gansu & 4 & 0.529 & Yunnan & 1 & 1.000 \\
\hline Yunnan & 1 & 1.000 & Yunnan & 5 & 0.527 & Gansu & 1 & 1.000 \\
\hline Gansu & 6 & 0.493 & Shaanxi & 6 & 0.448 & Sichuan & 6 & 0.442 \\
\hline Shaanxi & 7 & 0.479 & Sichuan & 7 & 0.372 & Shaanxi & 7 & 0.403 \\
\hline
\end{tabular}


Table 2: Total investment redundancy and targets for the provinces in 2011-2015

\begin{tabular}{ccccc}
\hline & $\begin{array}{c}\text { Employee } \\
\text { Redundancy }\end{array}$ & Target (person) & $\begin{array}{c}\text { Fixed Investment } \\
\text { Redundancy }\end{array}$ & Target (ten thousand) \\
\hline Inner Mongolia & 0 & 95867.000 & 0 & 73718.847 \\
Jilin & 0 & 108383.000 & 0 & 139939.776 \\
Sichuan & 5421.918 & 10284.082 & 0 & 23563.883 \\
Yunnan & 0 & 4673.000 & 0 & 12306.996 \\
Shaanxi & 0 & 3038.000 & 4718.010 & 7462.853 \\
Gansu & 0 & 11292.000 & 0 & 25873.322 \\
Xinjiang & 0 & 3718.000 & 0 & 9522.055 \\
\hline
\end{tabular}

Note: fixed asset investment is the constant price in 2010

\section{Analysis of the results}

Seen from the calculation results, overall efficiency of state-owned forest production is not very different among different provinces between 2011 and 2015. The comprehensive efficiency of Inner Mongolia, Jilin, Xinjiang, Yunnan and Gansu provinces is 1, indicating that DEA is valid with regard to state-owned forest production efficiency in these provinces. Efficiency of Sichuan and Shaanxi provinces is 0.442 and 0.403, respectively, DEA is invalid. The reason why DEA is invalid for state-owned forest production in Sichuan Province is staff redundancy and redundancy value is 5422 persons, with improvement target at 10284 persons. The reason why DEA is invalid for state-owned forest production in Shaanxi Province is fixed assets redundancy, and the redundancy value is 47.180 million yuan, with improvement target at 74.62853 million yuan.

Seen from annual point of view, in 2011-2015 five years, annual efficiency values of Inner Mongolia and Jilin provinces were 1, DEA was valid; except 2005, efficiency values of Xinjiang in the remaining four years were also 1, DEA was valid, but its efficiency value in 2005 was only 0.468 , ranking sixth among the seven provinces; efficiency values of Gansu Province in 2003, 2004 were 1, DEA was valid, afterwards, efficiency lowered, with efficiency values at $0.579,0.493$ and 0.529 , respectively in 2012 , 2013, and 2014, ranking fourth, sixth and fifth respectively among the seven provinces; efficiency values of Yunnan Province were 1 in 2011, 2014, DEA was valid, while efficiency values were $0.431,0.327$ and 0.527 , respectively in 2012, 2013, and 2015, ranking sixth, seventh and fifth respectively among the seven provinces; overall efficiency of Sichuan and Shaanxi provinces is low, except 2014 with efficiency value at 1 and valid DEA, efficiency of the remaining years was low with invalid DEA, and efficiency values were $0.442,0.320,0.508,0.372$ in 2011, 2012, 2013, 2015 respectively, ranking sixth, seventh, fifth and seventh respectively among the seven provinces; Shaanxi Province has similar situation as Sichuan Province, except 2013 with efficiency value at 1 and valid DEA, efficiency of the remaining years was low with invalid DEA, and efficiency values were $0.403,0.730,0.479,0.448$ in 2011,2012 , 2014 and 2015 respectively, ranking seventh, fifth, seventh and sixth respectively among the seven provinces.

The above analysis shows that forestry production efficiency is the highest in Jilin Province and Inner Mongolia Autonomous Region among the main state-owned forest regions, with valid DEA in terms of input-output; state-owned forest production efficiency in Yunnan, Xinjiang, Gansu, Sichuan and Shaanxi provinces is low, with invalid DEA and room for improvement. Wherein, state-owned forest 
production efficiency of Sichuan, Shaanxi provinces is the lowest, the two provinces need strive to improve efficiency, and actively catch up with other provinces.

\section{Acknowledgement}

Project Fund: Youth Fund Project of Humanities and Social Sciences Research of Ministry of Education (16YJC630029)

\section{References}

[1] Chames A, Cooper W W, Bodes E, Measurina the efficiency of decision making units[J], European Journal of Operational Research, 1978, 2: 429-444.

[2] Chames A, Cooper W W, Golany B, Foundations of data envelopment analysis for pareto-koopmans efficient empirical production functions[J], Journal of Econornetrics, 1985, 30(1): 91-107.

[3] Farrell M J, The measurmnent of production efficiency[J], Journal of Royal Statistical Society, Series A, General 1957. 120(3): 253 - 281.

[4] Wang Xiansheng, Guo Zhongxing, Study on non-agriculturization efficiency of agricultural land based on DEA method [J], Journal of Natural Resources, 2014 (6): 944-955

[5] Zhao Xiaofeng, Cheng Zongxing, Huo Xuexi, Analysis on Economic Benefit of Educational Input output in Agricultural and Forestry Higher Vocational Colleges[J], Journal of Northwest A \& F University(Social Science Edition) 2017 (5): 136-142

[6] Zeng Yuanandong, Li Xueshu, Wang Wei, DEA Analysis of Agricultural Production Efficiency in Yunnan Province [J], Journal of Yunnan Agricultural University (Social Science Edition) 2017 (11): $34-41$ 